CRÍTICA, Revista Hispanoamericana de Filosofía

Vol. XXIX, No. 85 (abril 1997): 3-39

\title{
EL ESPACIO DE LO PÚBLICO EN LA FILOSOFÍA POLÍTICA DE KANT
}

Nora RabotniKof

Instituto de Investigaciones Filosóficas

UNAM

El modelo de "publicidad" ilustrada, identificado con el uso público de la razón, con el abordaje a través del razonamiento desplegado a la luz del día de las cuestiones comunes y generales en un espacio potencialmente abierto a toda la ciudadanía, no ha cesado de ejercer cierta fascinación sobre el imaginario político moderno. Magistral aunque discutiblemente reconstruido por Habermas en su ya clásico Historia y crítica de la opinión pública, este modelo ha intentado ser tanto desmitificado desde la investigación histórica ${ }^{l}$ aunque también reivindicado desde un punto de vista normativo. En todos los casos, alguna versión de este espacio público ilustrado parece indisolublemente ligada al problema de la democracia. Y en todas sus versiones, como modelo normativo, esta imagen de la publicidad ilustrada parece articular de manera específicamente "moderna", los tres sentidos que convencionalmente se asocian al término "público": aquel que opone lo común

${ }^{1}$ Para una revisión crítica, véase Craig Calhoum (ed.), Habermas and the Public Sphere, MIT Press, 1992. 
y general a lo individual y particular, el que reivindica lo visible y manifiesto frente a lo oculto y secreto, y el que alude al carácter abierto e incluyente frente a lo cerrado, lo clausurado.

En efecto, en el vocabulario ilustrado, esa nueva esfera de la "publicidad" se identificará progresivamente con el espacio de formulación de los intereses comunes y generales. En segundo lugar, y de manera fundamental, el principio de publicidad se erigirá contra el secreto de Estado y pretenderá volver "públicas", en el sentido de desplegadas a la luz del día y vinculadas a la legitimación vía razonamiento público, a las leyes y medidas que afectan la generalidad de los privados. Por último, en su origen al menos, esa esfera de razonamiento público parece ser potencialmente accesible a todos, en virtud de los supuestos económicos de un orden natural pensado como esfera libre de coerción y poder.

En sus llamados escritos "políticos" y de otra manera en su Filosofía del Derecho, Kant rehabilitará el razonamiento público como instancia de control de la legislación y de las medidas políticas que afectan a la comunidad. El "uso público" de la razón cumple una función básica de ilustración, pero también va más allá. Con la formulación del principio de publicidad, el atributo de "público" (en el sentido de visible) se aplica al ejercicio del poder. Y en un último sentido también, en el supuesto de un uso público de la razón, es posible alcanzar la coincidencia pública, el consenso en la elaboración de la voluntad racional. El primer objetivo de este artículo es examinar el alcance político de dicha rehabilitación del razonamiento público. El segundo es formular una serie de problemas que, de Kant en adelante, volverán a plantearse cada vez que se trate el tema del espacio de lo público. Por último, el tratamiento de estas dos cuestiones me lleva a formular algunos interrogantes acerca de la concepción de la política en Kant. En estos textos, como 
en otros, la política aparece subsumida en la esfera de la moral y el derecho. Sin embargo, algunas indicaciones de Kant parecen reconocer un ámbito prudencial propio de la política que debe, no obstante, hacerse compatible con la moral y el derecho.

Si bien en la utilización general por parte de Kant, y en especial en la formulación del principio de publicidad, parece privar la oposición "público-secreto", sospecho que no siempre la formulación es inequívoca. De ahí que la discusión de los textos apunte a tratar de ver cómo se articulan los tres sentidos. Para ordenar la exposición, expondré el reconocimiento teórico y la justificación de la necesidad de institucionalizar un espacio público de debate y discusión, primero en relación con la función de ilustración. Analizaré luego el principio de publicidad como demanda de "visibilidad" en el ejercicio del poder (y las tensiones en la relación entre moral y política). El último término, la caracterización del espacio de lo público será analizado en relación con la formulación del consenso.

\section{Ilustración, cambio social y alcance político del espacio público}

La primera referencia que quisiera desarrollar es la que remite a la "libertad de pluma" y a la discusión pública como parte del proyecto ilustrado. Conocida es la caracterización de Kant de la Ilustración como "salida de la minoría de edad", 2 como capacidad humana para poder "pensar por sí mismo". Esa autonomía frente a la tutela exterior es considerada una conquista difícil para el individuo aislado; en cambio es "más fácil que el público se ilustre por sí mismo, y hasta, si se le deja en libertad, casi inevitable". 3

2 E. Kant, “¿Qué es la Ilustración?, en Filosofía de la Historia, FCE, 1978, p. 26.

3 Ibid. 
La ilustración del público (hoy diríamos el desarrollo de una cultura política democrática) sólo puede lograrse poco a poco a través de la libertad otorgada a todos de hacer uso público de la razón. En este caso Kant juega de manera un poco desconcertante con los adjetivos privado y público. Uso público es el que se hace ante "el público" en calidad de "maestro", de entendido que opina sobre los asuntos de interés general, "de docto que se dirige por medio de sus escritos al público propiamente dicho, es decir, al mundo". Uso privado es aquel que se ejercita en calidad de funcionario, de miembro de una organización especializada, en cuyo caso, el deber consiste en obedecer y cumplir eficientemente la tarea. ${ }^{4}$ Esta imprescindible tarea de ilustración colectiva sólo es posible en el ámbito de la libertad de expresión y de opinión. Ambas son, pues, condiciones de posibilidad de este "uso público" de la razón.

La discusión pública fomenta la ilustración mutua entre el público y la autoridad. El Soberano debe conceder "la facultad de hacer conocer públicamente la opinión sobre aquello que en los decretos del Soberano parece una injusticia en relación con la cosa pública" ${ }^{5}$ El público se ilustra a través de la exposición pública de la verdad y el gobernante se entera del estado de los asuntos públicos, lo cual contribuye a mejorar su capacidad de decisión y a evitar errores de juicio. Pensar en voz alta es entonces beneficioso para el público y el gobierno. Éste sería el primer sentido

4 Recordemos los ejemplos de Kant: el oficial en el cuartel, el clérigo en su iglesia, incluso el ciudadano en el cumplimiento de sus obligaciones civiles, como el pago de impuestos. En este caso, el desdoblamiento se produciría al interior del ciudadano, en su carácter de súbdito y de ciudadano propiamente dicho o de contribuyente y miembro del público.

5 "On the Common Saying: This May be True in Theory but It Does no Apply in Practice", en Kant's Political Writings, Cambridge, 1970 (en adelante TP). 
más general del uso público de la razón como método de ilustración.

Sin embargo, esta formulación no carece de problemas. En primer lugar, como dije, la utilización de los adjetivos privado y público que se refieren al uso de la razón resulta desconcertante. A primera vista Kant parecería estar admitiendo una restricción de la libertad de conciencia, en tanto que el uso privado aparece restringido en la práctica por la obediencia, y al mismo tiempo se aboga por algo que podría entenderse como libertad para disentir expresamente. Pero con "uso privado" de la razón Kant no se refiere a la libertad de conciencia en el plano privado, sino al problema del uso político de la razón para intentar cambiar el estado de cosas dado. Kant no restringe la libertad de juicio y de conciencia sino que, al menos en el texto explícito, separa cuidadosamente la actuación de los ciudadanos en calidad de sabios o simplemente de ciudadanos, del desempeño de tareas que deben ejercitarse profesionalmente de manera "casi automática", de la actuación en "lugares" de ejercicio del poder efectivo o, lo que es igual, de los ciudadanos en el ejercicio de funciones públicas. En el caso del "uso privado", prima la obediencia por sobre la discusión.

Si esta glosa poco feliz de la afirmación de Federico de Prusia, "Razonad todo lo que queráis y sobre lo que queráis, pero obedeced", es puesta en relación con la evaluación "política" de la Revolución (no necesariamente con el juicio histórico-filosófico), las interpretaciones son tajantes. Para algunos intérpretes, sobre todo si se compara esta posición con la teorización del derecho de resistencia de Locke, Kant no estaría haciendo otra cosa que confirmar las prácticas del despotismo ilustrado prusiano. La relación entre discutir y obedecer remite una vez más al conocido repudio kantiano al derecho o delito de resistencia, sublevación o sedición, y ello puede interpretarse como la primacía del valor "orden" por encima del, en todo otro sentido tan 
caro, valor libertad. En cualquier caso Kant, al igual que Hobbes, es explícito al afirmar que la resistencia o el cuestionamiento "político" de las leyes y medidas del Estado disolverían las bases mismas de la constitución civil, liquidando así las bases racionales de toda convivencia política. En este caso, está en juego la supervivencia del cuerpo social como tal y ello se impone por sobre cualquier ejercicio de la autonomía del individuo. Para nuestra reconstrucción, esta distinción entre uso público y uso privado permite dos interpretaciones matizadamente diferentes que, en ambos casos, oponen reforma a revolución.

En primer lugar, cierta lectura funcional sería la siguiente: Kant reconoce la necesidad de que las distintas funciones se cumplan; algo así (en vocabulario contemporáneo) como que los subsistemas sigan funcionando (que los maestros enseñen, los burócratas administren, los soldados obedezcan) independiente y paralelamente al proceso de discusión pública. El sistema no colapsa ni se paraliza. El uso público de la razón, encerraría también la idea de que sólo a partir de la visión ilustrada (especializada) sobre un aspecto o función es posible generar la información y discusión colectiva y, por lo tanto, la educación de ese público. En ese sentido, la posición kantiana encerraría una apuesta fuerte por el papel transformador de las elites ilustradas. El cambio gradual y no anárquico se acompaña y sostiene en la educación política del público. En este caso, dicho contemporáneamente, la complejidad se tiene en cuenta y la gobernabilidad se sostiene. También podríamos afirmar que, en este caso, cierto "realismo" permea la autopercepción del alcance político de la discusión ilustrada. Se trata de una contribución imprescindible a la ilustración colectiva, al progreso, al desarrollo político, a la legalidad, incluso un avance en la reforma de aspectos parciales, pero no de una alteración sustantiva de las relaciones de poder existentes. En todo caso, el "uso privado", en esta particular 
acepción, parece "poner entre paréntesis" el problema del actuar moral. $\mathrm{O}$ dicho de otra manera, el reconocimiento y la obediencia al poder político nos condenan a la heteronomía.

Una interpretación más radical pondría el acento en "otra" autopercepción del alcance político de la discusión ilustrada. El uso público de la razón aspira a ilustrar al poder, no a disputarlo. No se erige en otro "poder" que contrasta y se opone al poder existente sino que aspira, en última instancia a diluir, a través del proceso infinito de ilustración, el núcleo de arbitrariedad o de dominio arbitrario, reconduciendo la voluntad a la razón, el dominio a la argumentación. ${ }^{6}$ En este caso, la dimensión utópica priva y la aspiración a racionalizar el poder se confunde con su límite, es decir, con la disolución de toda relación de poder.

Ambas interpretaciones apuntan a la idea de cambio gradual, en obvia contraposición a la ruptura drástica. Pero mientras la primera enfatiza el aspecto de la reforma del poder o de su ejercicio, la segunda iría más allá, hacia el horizonte de su disolución, encerrando la promesa de liberación de todo poder como coacción exterior. Los elementos que abonan ambas interpretaciones están presentes en estos textos kantianos y las dos tendrán desarrollos y "encarnaciones" históricas diversas. Una de ellas será la confianza en la ilustración progresiva entendida como progreso cultural y moral y como conquista gradual de la autonomía, es decir, la apuesta por la Filosofía de la Historia de cuño progresista. Otra, será la división estricta entre dos ámbitos, uno sometido al poder y la obediencia y otro de ejercicio de la autonomía (sea este ámbito el de la República de las Letras, de la sociedad civil, de las asociaciones voluntarias,

${ }^{6}$ Ésta, me parece, es la interpretación de la pretensión política ilustrada del Habermas de Historia y crítica de la opinión pública. 
etc.). Una tercera irá más allá, reconocerá los límites de las armas de la crítica público-ilustrada, y conservando la promesa de disolución del poder, afrontará la crítica de las armas. Se tratará en este caso de derrocar al poder y de construir "otro poder" que termine con todo poder.

En el caso de Kant, la conciliación entre espíritu de libertad, uso público de la razón y obediencia está marcando la distinción entre el ámbito de la crítica y la jurisdicción política del estado, entre la búsqueda desinteresada de la verdad y la esfera de la política. En todo caso, en este primer "uso público" de la razón, el público que aparece como espectador y eventual actor de esta discusión ilustrada es básicamente un público intelectual, no político, es decir, el público en su función de difusor y receptor de la cultura, no uno que vota o participa. Sus límites son los que el Estado le asigna, y el poder es ilustrado justamente en tanto acuerda un derecho de autonomía a un espacio que él mismo ha delimitado.

2. El principio de publicidad como puente entre moral, derecho y politica

La formulación más nítida del principio de publicidad la encontramos en el Apéndice a La paz perpetua. No deja de llamar la atención que el encuadre de su formulación esté dado por la polémica abierta de Kant contra cierta versión del realismo político. El texto resulta revelador de algunas ambigüedades presentes en la concepción kantiana de la política. La política se diluirá a veces en la moral, siendo un caso de aplicación del imperativo categórico, subsumida en la actividad del juicio determinante. Otras veces, parece tener una dinámica propia, más cercana a la actividad del juicio reflexionante. El marco general es la discusión contra el realismo político, o contra "cierto" realismo que Kant caracteriza como aquel que ubica la política en el terreno de 
la sabiduría prudencial. Por supuesto, no es el estatuto de la política lo que le preocupa a Kant, sino el de la moral: "si no hay libertad ni ley moral fundada en la libertad; si todo lo que ocurre y puede ocurrir es simple mecanismo natural, entonces la política - arte de utilizar ese mecanismo como medio de gobernar a los hombres - es la única sabiduría práctica, y el concepto de derecho es un concepto vano". 7

Pero si nuestra pregunta se dirige hacia la política ¿qué nos está diciendo Kant? ¿Que la política es el arte de utilizar el mecanismo natural como medio de gobernar y que por encima de esto que es la política se yergue la moralidad? ¿O que la política, referida al concepto de derecho es otra cosa o puede ser otra cosa?

En Kant encontramos un matiz que hace que esta naturaleza de la política permanezca ambigua: a veces, parece reconocerla como esfera independiente y ámbito prudencial que puede y debe, no obstante, ser coincidente (por otras vías) con la moralidad. Otras veces, esta independencia se diluye completamente: es una extensión de la moralidad o del actuar práctico en general.

Pero vayamos por partes. Antes de tratar de aclarar dicho matiz, hay que señalar que Kant en primer lugar despeja el terreno para colocar la política en relación (todavía problemática) con la moral. Es decir, los problemas, las tensiones, las comparaciones y las soluciones surgirán del terreno de la moralidad y no del conocimiento (es decir, de entender la política como ciencia) o del juicio estético (juicio reflexionante). ${ }^{8}$ En términos modernos, la política es directamente colocada en la esfera de lo práctico-jurídico y

${ }^{7}$ La paz perpetua (en adelante PP), p. 136.

${ }^{8}$ Por el acercamiento entre juicio estético y juicio político, Hannah Arendt considerará la Crítica del juicio como el más político de los textos kantianos. Por ello también, a partir de este texto parece difícil sostener cualquier interpretacion que apunte a la política como prudencia. Por ello también, interpretaciones como la de Lyotard justificarán 
no de la expresividad estética o de lo cognitivo-técnico. Para ello, Kant descarta dos opciones: la posibilidad de hacer derivar el actuar político del conocimiento del desarrollo futuro de la naturaleza y el intento de basar la justificación del actuar político en una antropología negativa. Con ello, Kant nos da algunos indicios sobre cómo "no" debemos pensar la política.

Kant parece descartar cualquier determinismo o cualquier horizonte de transparencia de la acción política ya que "la razón no tiene la suficiente penetración para conocer totalmente la serie de causas antecedentes y determinantes, que podrían permitir una segura previsión del éxito favorable o adverso que ha de rematar las acciones de los hombres, según el mecanismo de la Naturaleza". Si el llamado "realismo político" pretende basarse en la posibilidad del conocimiento científico de las conexiones causales entre las acciones humanas, su pretensión no es más que una ilusión. Ni control de la fortuna a través del ejercicio de la virtud como anticipación y cálculo según Maquiavelo, ni horizonte de calculabilidad racional que hace posible una decisión responsable (es decir, una decisión que se hace cargo de las consecuencias, precisamente no previstas). Ni la ciencia, ni la Filosofía de la Historia (al menos en este texto) pueden fundar una política realista. No puede haber un conocimiento del devenir político como mecanismo causal completo y, por lo tanto, "Júpiter se halla sometido al destino". La política no es un cálculo racional ni un conocimiento anticipado de causas y consecuencias.

En segundo lugar, la objeción se dirige contra una antropología negativa basada en el conocimiento empírico de la naturaleza humana, contra una especie de empirismo en la política. La fundamentación en una antropología negativa

la exclusión de los textos referidos al derecho para la consideración de lo político. 
(que, sin embargo, Kant comparte en otros textos) presenta otros problemas. En primer lugar, excluye desde el inicio toda relación posible entre moral y política, descartando como pura ilusión toda apelación a los principios morales (aquí el argumento es similar al de la consideración de la Historia, vista desde el punto de vista de la Naturaleza). Pero también, parece decirnos Kant, llevaría a circunscribir el problema a la cuestión empírica del origen de la situación de derecho, es decir, plantearía como primer problema la conformación de una voluntad política capaz de instaurar el derecho, un monopolio de la coacción que fundara el derecho o la situación de derecho. ${ }^{9}$ A partir de lo problemático de este origen, el empirismo político descartaría como ilusión la posibilidad del Estado de Derecho. Kant, sabemos, resolverá el problema separando el problema del origen fáctico del Estado y del Derecho de su fundamentación racional.

El "moralista político", aquel que resuelve el problema de la tensión entre política y moral por la vía de predicar una moralidad ad hoc para el arte político (¿Maquiavelo?), fundará su acción en los datos proporcionados por una antropología negativa y en la posibilidad de un conocimiento ajustado de la causalidad natural. Aquí el problema se resolverá en términos de habilidad política y de un enfoque técnico de lo que está en juego, en un esquema mediosfines. Las proposiciones estrictamente cognitivas, los "conocimientos" (en sentido estricto) en el campo de lo his-

9 “Hace falta además, para resolver tan difícil problema, la unidad colectiva de la voluntad general; hace falta que todos juntos quieran ese estado para que se instituya una unidad total de la sociedad civil. Por tanto, en las diferentes voluntades particulares de todos es necesario, además, una causa que las una, para constituir la voluntad general, y esa causa unitaria no puede ser ninguna de las voluntades particulares. De donde resulta que, en la realización de esa idea - en la prácticael estado legal ha de empezar por la violencia, sobre cuya coacción se funda el derecho público." PP, p. 135. 
tórico político justificarán así la evaluación de la historia como desorden y una política pragmática basada en el hecho (empíricamente constatable) de que "todas las formas de gobierno ofrecen en la historia ejemplos que se contrarían". ${ }^{10}$ El "político moral", en cambio, es aquel que se rige por principios, más allá de los fines materiales y del cálculo de medios. La prudencia, en el caso del político moral, parece ser una virtud auxiliar, que rige en el gradualismo, en la utilización del tiempo y en la habilidad para aprovecharse de los momentos favorables. En general, los ejemplos que cita Kant con respecto a los peligros potenciales del "moralismo" en política tienen que ver casi exclusivamente con la precipitación (y con la revolución).

Frente a esta oscilación de la voluntad provocada por la ponderación de fines y medios, los principios ofrecen al "político moral" un puerto seguro que abriga a todos. Ya no se trata entonces sólo de la concordancia entre prudencia y moralidad, sino del punto de vista moral guiado por el principio formal: "obra de tal modo que puedas querer que tu máxima deba convertirse en ley universal, cualquiera que sea el fin que te propongas". ${ }^{11}$ Se trata entonces de la aplicación del imperativo categórico al terreno de la política, por intermedio del derecho. Sin embargo, el terreno de la política obliga a Kant a dar un paso más y a justificar también tal aplicación a partir de la realización de los fines: "si procuramos acercarnos al ideal de la razón práctica y a su justicia, el fin propuesto (la paz u otro de los grandes fines políticos) vendrá sólo". ${ }^{12}$ ¿De dónde surge esta garantía de que con la independencia de la ponderación de fines, medios y consecuencias posibles, la aplicación rigurosa de los principios, traerá, además de la certeza del actuar mo-
${ }^{10} \mathrm{PP}$, ibid.
11 PP, p. 143.
12 PP, p. 144. 
ral, la realización de los fines? Esta “promesa" parecía no hacer falta en el terreno de la Razón Pura Práctica. No se trata aquí del Bien como objeto necesariamente asociado al actuar moral, se trata de un fin político. ¿Es que el actuar por deber en política necesita también de una justificación en términos de consecuencias para el colectivo? ¿En qué se basa este resultado "no buscado" del actuar moral en política?

Sabemos la respuesta kantiana:

Esto sucede porque la voluntad universal, dada a priori —en un pueblo o en la relaciones entre varios pueblos- es la única que determina lo que es derecho entre los hombres; esta unidad de todas las voluntades, si procede consecuentemente en la ejecución puede ser también la causa mecánica natural que provoque los efectos mejor encaminados a dar eficacia al concepto del derecho. ${ }^{13}$

Una vez más ¿qué nos está diciendo Kant? Podríamos pensar que se trata de otra forma de resolver la cuestión vía Filosofía de la Historia. Una especie de "astucia" de la moral que realiza a la larga fines no propuestos o no afirmados como motivación de la acción. Sin embargo la respuesta va por otro lado. En primer lugar, la voluntad universal a priori se transforma en la unidad de las voluntades (individuales), la voluntad general en voluntad de todos. En segundo, "proceder consecuentemente en la ejecución del derecho puede obrar como causa mecánica natural para dar eficacia al concepto de derecho". ¿No nos está diciendo Kant que actuar conforme al derecho instaura prácticas y rutinas que terminan por dar eficacia al concepto de derecho? ¿Que el actuar apegado al derecho, como si el derecho efectivamente fuera la norma de regulación

13 PP, pp. 145-146. 
de la convivencia, termina por otorgar eficacia empírica al concepto de derecho? ${ }^{14}$

Pero esta interpretación que apunta a ligar la res pública nouménica con la res pública fenoménica, la voluntad $a$ priori con la voluntad de todos, y el actuar por deber con el actuar según el derecho, es contradicha por la interpretación de Kant del proverbio: "Hágase justicia y perezca el mundo". Si hasta ahora se había subrayado que los fines aparecían como consecuencia no buscada del actuar por deber, en el final de la primera parte de este apéndice, el rigor de la formulación no deja lugar a dudas:

las máximas políticas no deben fundarse en la perspectiva de felicidad y ventura que el Estado espera obtener de su aplicación, no deben fundarse en el fin que se proponga conseguir el Gobierno, no deben fundarse en la voluntad, considerada como principio supremo —aunque empíricode la política; deben por el contrario, partir del concepto puro del derecho, de la idea moral del deber, cuyo principio a priori da la razón pura, sean cualquiera las consecuencias físicas que se deriven ${ }^{15}$ (las cursivas son mías).

Kant descarta aquí radicalmente cualquier interpretación pragmática o prudencial de la política.

$\mathrm{Y}$ es aquí donde Kant introduce la fórmula trascendental de la publicidad, forma del concepto puro de derecho, en su versión "negativa": "Las acciones referentes al derecho de otros hombres son injustas, si su máxima no admite publicidad." Se trata de un principio cierto e indemostrable y de un principio "jurídico", que atañe a las relaciones de derecho, o sea a las acciones externas. El ejemplo de Kant, en relación con el derecho político, vuelve sobre la legitimidad

14 Es decir, que resulta no en un incremento de la moralidad sino de la legalidad de las acciones debidas, cualesquiera que sean los móviles (interés propio bien entendido, honor, etc.).

15 PP, p. 149. 
de la revolución. Es ahora el principio de publicidad el que nos "ahorra" discusiones ociosas. La "reserva" del derecho de resistencia, significaría preservar la posibilidad de un doble poder o de la doble soberanía. Aquí el argumento es más hobbesiano que lockeano. Una máxima que previera situaciones de doble poder o de cuestionamiento de la soberanía sería contradictoria con el propósito mismo de la instauración del Estado. Como tal no podría ser pública, como tal no puede ser considerada justa.

El caso es más claro en términos del derecho internacional o derecho de gentes. Los ejemplos de Kant refieren al cumplimiento de los compromisos entre los estados, a la ilegitimidad del "ataque como la mejor defensa", a la anexión de territorios y al derecho de ciudadanía mundial. Sin embargo, ¿qué quiere decir que este tipo de acciones sean incompatibles con la publicidad? ¿Que el incumplimiento de las promesas o que la solución por la fuerza aun en condiciones que se evalúan como de peligro son contradictorias con la moral? Desde ya. Se podrían multiplicar los ejemplos kantianos y concluir entonces que toda consideración estratégica es directamente inmoral, o comprobar con Maquiavelo, que ciertas máximas de la habilidad política tienen necesariamente que permanecer secretas. Es decir, que las consideraciones de eficacia política son necesariamente contradictorias con la exigencia de publicidad y, por lo tanto, irremediablemente inconciliables con la moral.

Sin embargo, frente a esta consideración tan radical, podemos reconocer que Kant nos da ejemplos en los que la habilidad o la prudencia política coincide con la moral: el aplazamiento de reformas hasta mejor ocasión (en caso de peligro exterior), por ejemplo. En este caso, la consideración estratégica (ocasión, relación de fuerzas, amenaza externa) parece privar y se trata de ver si su ejecución coincide o no con el derecho y la moral. En todo caso, dejemos la cuestión reconociendo simplemente que Kant nos 
pone ejemplos en los que se da o no la concordancia. Más interesante, aunque igualmente problemática para nuestra discusión, parece ser la formulación "afirmativa" del principio trascendental: "Todas las máximas que necesiten de la publicidad para conseguir lo que se proponen, concuerdan a la vez con el derecho y la política reunidos."16 Pues "si solo por medio de la publicidad pueden alcanzar el fin que se proponen, es porque concuerdan con el fin general del público: la felicidad". La fundamentación es sorprendente y desconcertante: "el problema propio de la politica es ése: conseguir la felicidad del público, conseguir que todo el mundo esté contento con su suerte" 17 (las cursivas son mías).

¡Extraño viraje! Antes Kant nos había dicho que la consideración debía hacerse con independencia de los fines y sobre todo con independencia de la felicidad. Aunque aclara que este caso no hace referencia a las condiciones empíricas de la felicidad (como materia de la ley) sino a la forma de la ley, de todos modos "las condiciones formales de la felicidad del público" (es decir, aquellas que no definen el contenido de la felicidad, pero sí garantizan la libertad de buscarla y lograrla) hasta ahora no habían aparecido. De pronto el principio de publicidad ya no es sólo piedra de toque de la corrección (o más bien incorrección moral) de las máximas políticas, sino que ahora asume la función de articular la política (como consecución de la felicidad del público) con el derecho como formulación de las condiciones y garantías de libertad para esa búsqueda de la felicidad (como "sistema" de las libertades que permite

16 Según el Habermas de HC, en este punto Kant le atribuye a la publicidad una nueva función que, como tal, no puede ser estrictamente encuadrada dentro del sistema kantiano.

17 E. Kant, PP. 
armonizar los fines particulares), con la moral en la forma del imperativo categórico.

En este punto, la publicidad de las normas permite aunar entonces la formulación explícita en forma de ley, la aceptación por parte del público y las condiciones formales y generales para el logro de fines particulares: Publicidad, consenso y generalidad de la ley. "Necesitar de la publicidad" significaría aquí necesitar del concurso o de la aprobación del público. Kant parece hacer referencia a algo más que a la mera formulación pública (opuesta a secreta), que correspondería como forma a todo derecho. Refiere en cambio a una suerte de "aprobación" o prueba de la concordancia de la norma con las condiciones para la felicidad privada, es decir, con los derechos individuales. La publicidad operaría entonces contra el designio secreto (privado) del político, funcionando como test de su concordancia con los derechos del hombre y del ciudadano y con el bienestar de la comunidad. El público que antes hacía uso público (abierto) de la razón para discutir, aparece ahora de otra manera (¿dando su consentimiento? ¿formulando? ¿expresándose?) en relación con el derecho. Pero ello nos lleva a un tercer problema. ¿Cómo entra entonces el público concreto en la formulación de la ley? ¿Se produce aquí una extensión del alcance político previamente asignado por Kant a la discusión pública? ¿Cómo podemos hablar de algún tipo de voluntad pública (común) que deba expresarse públicamente (abiertamente) para garantizar las condiciones de la felicidad privada?

3. La legitimidad de la legalidad y el papel de la opinión pública

En sentido más fuerte la discusión pública no sólo ilustra a gobernantes y gobernados, no sólo debe ser tomada en cuenta como referente de las normas, sino que genera 
consenso y, diríamos hoy, es el correlato empírico de la legitimidad racional de las leyes generales. El público que hace uso público de la razón y que en el terreno privado, qua individuo busca su felicidad y bienestar por los caminos y alternativas ofrecidas en el terreno social, estaría en condiciones de dar su consentimiento racional a la ley justa, es decir, a aquellas normas que en un sentido general hacen compatible la libertad de cada quien con la de los demás.

Recordemos que la crítica de Kant al "Estado paternalista" es bifronte: critica su fundamentación en una voluntad privada (particular) y objeta la tutela estatal a los súbditos, derivada a su vez del principio de benevolencia. Es la fundamentación privada (la voluntad del monarca) de lo público (como cosa general y común a todos) la que termina negando la naturaleza privada de la felicidad, imponiendo una concepción del bien o de la felicidad. La benevolencia termina transformando los deberes en favores y los derechos en logros discrecionales que remiten todos a una voluntad privada (particular), a un tipo de acción cuya máxima es oscura, a una forma de despotismo. Es entonces necesario afirmar una voluntad pública (común, general y formulada explícitamente en la ley) que en última instancia sea garantía y protección de la libertad de las personas y el marco legal para la consecución de la felicidad privada.

Tal vez este punto, que marca el cruce entre derechos individuales (naturales) y autonomía política, entre felicidad y voluntad pública, sea el más oscuro. Es también el lugar donde la sedimentación de las interpretaciones parece inseparable de la intención original de Kant. Cito sólo algunos problemas conexos: la concepción republicana de Kant (diferente en aspectos sustantivos de lo que hoy se reivindica como tradición republicana), ${ }^{18}$ en la que se

18 Me refiero a la recuperación de las tradiciones del humanismo 
subraya el aspecto del imperio de la ley, su rechazo de la democracia (identificada con el despotismo popular), la fundamentación no utilitarista del liberalismo. Y quizá de manera más importante la ruptura que introduce Kant con su idea de Estado de Derecho que abrirá (hasta nuestros días) la discusión en torno a la naturaleza de la legalidad y su legitimidad. En ese sentido, uno de los problemas que hereda Kant de la tradición jusnaturalista es el de la relación entre el estadio natural y el estadio civil. En Kant esta relación problemática aparecerá reduplicada por el problema de la relación entre la comunidad empírica y el Estado como idea de razón. Por lo pronto apuntemos que el Estado de Derecho (no separado aún de la sociedad civil que en Kant es un estadio jurídico ) no es inmediatamente funcional al estadio natural sino que, como idea de razón, hace abstracción de dicho estadio. El Estado parece haber perdido teóricamente conexión empírica con la historia y la sociedad natural y, de este modo Kant, sobre la huella de Hobbes en este punto, abre el camino para pensarlo desde una teoría de las condiciones ideales de una actividad racionalizadora y ordenadora de las relaciones interpersonales. Así, ni el contrato fundador ni el Estado son hechos históricos. Al atribuirles sólo la realidad práctica de una idea de razón según la cual el Estado puede ser construido a priori y así puede ser pensada su legitimidad, Kant separa la cuestión del fundamento jurídico del Estado del problema del origen. En términos más concretos el origen histórico de la constitución no es lo que fundamenta la obligación de obedecerla, ni el derecho a cuestionarla (en caso de ilegalidad o ilegitimidad). El ingreso en la sociedad estatal es un imperativo de razón, frente al cual los individuos que viven en el estado de naturaleza tienen la

cívico y del republicanismo en las que se enfatiza la noción de libertad positiva, participación, ciudadanía activa, bien colectivo, etc. 
obligación de obedecer: el fundamento jurídico del Estado está en su necesidad racional, no en el cálculo interesado ni (en principio) en el perfeccionamiento o garantía de la situación natural. ${ }^{19}$

"Una ley pública que define para todos lo que está permitido y prohibido por derecho, es el acto de una voluntad pública, de la que procede todo derecho y que, por tanto, no es capaz de hacer injusticia a nadie. Y esto requiere de la voluntad de todo el pueblo (ya que todos deciden por todos y cada uno por sí mismo)." ${ }^{20} \mathrm{El}$ carácter "público" de esta voluntad hace referencia aquí a los tres sentidos que manejamos. En efecto, se trata de la voluntad común y general frente a la voluntad particular del monarca. Es también una voluntad explícita ya que su expresión es la ley. Y por último, remite en términos empíricos a un proceso o procedimiento de formulación de dicha voluntad que está abierto (en principio a todos), y cuya aplicación no admite exclusiones ni privilegios.

En el primer sentido de público, la voluntad pública, es y no es voluntad de todos. Lo es en tanto expresión de la soberanía popular. No lo es en tanto no es la voluntad concreta de los individuos en su particularidad (omnes et singuli), sino expresión de su universalidad como miembros del pueblo o universi. En este caso el carácter fenoménico debe trascenderse, pues a partir de sí misma la libertad natural sólo puede generar una libertad salvaje. El problema que Rousseau intentaba resolver vía la transformación del "hombre" en ciudadano, del interés privado en interés

19 Sin embargo, por otro lado, también la insociable sociabilidad y la competencia generalizada, aparecen como motores de un progreso hacia una situación social en la que la mayor libertad (y, por tanto, antagonismo entre sus miembros) coexista con la especificación y preservación de los límites de esa libertad de modo de coexistir con la libertad de todos.

20 TP, p. 77. 
público, y que no suponía tanto la abstracción de los fines particulares como la renuncia a ellos, aparece aquí resuelto en la figura de la voluntad legisladora a priori que surge de la abstracción de la felicidad privada y de tres principios a priori: la libertad en tanto hombres, la igualdad en tanto súbditos y la autonomía en tanto ciudadanos.

Es ésta la voluntad que instaura la constitución civil, como ley suprema soberana que regula normativamente la estructura de poder y garantiza los derechos individuales. Nuevamente, el rechazo del "contrato histórico" sirve para distinguir la legitimidad de origen de la legitimidad "racional". ${ }^{21}$ El contrato como idea de razón supone que "se puede obligar a cualquier legislador a hacer sus leyes de tal modo que podrían haber sido producidas por la voluntad unificada de una nación, y a considerar a cada uno de los súbditos, en tanto puede pretender ser ciudadano, como dando su consentimiento a la voluntad general. Ésta es la prueba de corrección de cualquier ley pública".22 Así, la figura del contrato como "idea generadora" de sociedadestatal (y de norma fundamental de convivencia, de constitución en el sentido moderno) pasa a ser un mecanismo de prueba de la legitimidad de "cualquier ley pública", sin perder ni su referencia al consenso ni su estatuto de "idea de razón". El legislador debe legislar "como si" el pueblo diera su consentimiento.

Y aquí es donde se vuelve más problemática la relación entre "consenso ideal" y "consenso empírico", entre "voluntad constituyente" y "voluntad política" o, en otro len-

21 "Este supuesto (el del contrato histórico) implicaría que tendríamos que probar primero, a partir de la historia, que una nación cuyos derechos y obligaciones nos fueron trasmitidos, en realidad acordó realizar tal acto, y nos legó algún registro auténtico o instrumento legal, oral o escrito, antes de que pudiéramos considerarnos ligados por una constitución preexistente." TP, p. 79.

22 TP, 79. 
guaje, entre la legitimidad de las normas fundamentales (que pueden ser reconocidas por todos los hombres libres e iguales) y la legitimidad derivada, referida a normas particulares, que pueden resultar incapaces de consenso universal. Es decir, entre un consenso de base, originario y fundamental (aunque no histórico) y un consenso "puntual" en torno a una serie de cuestiones cuya resolución legítima deriva de la legitimidad de la norma fundamental (lo que será después su carácter constitucional o anticonstitucional), o bien deben ser legitimadas "de vez en vez". En el fondo, cabe preguntarse si los tres principios proporcionan un criterio practicable de formación de la voluntad política.

Si la ley es tal que no fuese posible que un pueblo entero diera su consentimiento (por ejemplo, si estipula que cierta clase de súbditos fuera privilegiada como clase dominante hereditaria), es injusta; pero si es al menos posible que un pueblo diera su consentimiento, es nuestro deber considerar que la ley es justa, incluso si el pueblo tuviera en ese momento una actitud o estado de ánimo tal que probablemente rechazaría otorgar su consentimiento si fuera consultado. ${ }^{23}$

Recordemos el ejemplo kantiano de los impuestos para la guerra, con el cual intenta mostrar cómo el principio de igualdad en tanto súbditos viene a zanjar la disputa. Un impuesto, proporcionalmente aplicado a todos para sufragar una guerra, no podría ser considerado injusto porque se considere que la guerra es innecesaria. Kant argumenta que los ciudadanos no están autorizados a juzgar esta cuestión (si la guerra es necesaria o el impuesto hace falta) si "es al menos posible que la guerra sea inevitable y el impuesto indispensable" y, por tanto, el impuesto debe ser considerado justo. Siempre y cuando la distribución de las

${ }^{23}$ Ibid., p. 80. 
cargas sea pareja. Si éste no es el caso, si algunos fueran penados y otros exceptuados, es fácil pensar que un pueblo entero jamás podría dar su consentimiento a una ley de este tipo. El ejemplo es interesante por varias razones. En primer lugar, la concordancia con los principios es un cálculo que atañe sólo al juicio del legislador al formular la ley. Es decir, el conjunto del pueblo puede ser "incorporado" en el razonamiento del legislador o, dicho de otra manera, uno sólo puede reproducir o verificar el razonamiento de todos. En segundo lugar, hay ciertos elementos contextuales que escapan totalmente a la consideración del público. En este caso la inevitabilidad de la guerra y la necesidad del impuesto, no son ni deben ser sometidos a consideración. Tienen que ver con los fines y con el bienestar y, en última instancia, con el cálculo de medios, que pueden ser o no "prudentes" dentro del margen ofrecido por su concordancia con el principio del derecho. ${ }^{24}$ Pero en todo caso ese cálculo prudencial no es objeto de examen público. En tercer lugar, de nuevo parecen confundidos dos niveles, el de los principios de la legislación general concordantes con la legislación moral, que son independientes de la consideración de los fines y de la felicidad, y el de una serie de medidas particulares que, por el contrario, debe dar cuenta de ellos. Así, podríamos decir, la juridicidad de una medida podría ser universalmente aceptada, y por esa vía su corrección moral. Lo que sería discutible (nunca desobedecido) es el contenido del mandato y su "adecuación" para el logro de la felicidad. También aquí la piedra de toque para

24 "El jefe de estado debe ser autorizado a juzgar por sí mismo si tales medidas son necesarias para la prosperidad de la comunidad, prosperidad necesaria para mantener su fuerza y su estabilidad tanto internamente como en función de los enemigos externos. El legislador puede en verdad, errar al juzgar si las medidas que adopta son prudentes, pero no al decidir si la ley armoniza o no con el principio del derecho." Ibid. 
el convencimiento racional de quienes obedecen (no para su obediencia que es incuestionable aun en el caso en que "el poder del estado o de su agente, el jefe de estado, haya violado el contrato original al autorizar al gobierno a actuar tiránicamente y, por lo tanto, ante los ojos del súbdito ha resignado su derecho a legislar" $)^{25}$ es la concordancia con los derechos fundamentales. La aceptación por parte del público no se vincula así a un contenido concreto de la decisión. Se vincula al contrato original, a la preservación de los derechos y a la legitimidad de la fuente de la ley. Dos elementos se sustraen a la consideración del público: un núcleo "prudencial" que permanece ajeno a las consideraciones del público (que tiene que ver con el cálculo de medios y con el logro del bienestar), y otro núcleo que remite al juicio acerca de cómo la constitución debe ser administrada, que tampoco es competencia de los súbditos. ${ }^{26}$

El ejemplo y el tema sacan a la luz este problema que no está suficientemente clarificado por Kant. ¿Qué es, o cómo se constituye esa voluntad pública y cuál es su alcance? En la tradición jusnaturalista, el contrato social como idea de razón apela a la idea de asamblea constituyente que debe alcanzar un doble acuerdo: sobre los derechos fundamentales, cuya tutela y promoción constituye el fin de la comunidad política y sobre las formas del poder político como medios para el logro de esos fines. Es decir, un acuerdo racional sobre los principios y un acuerdo sobre las instituciones y procedimientos para llegar a la formulación de decisiones colectivas aptas para la realización y preservación de los derechos. Kant no siempre es claro acerca de la distinción entre la constitución como carta de principio y como tratado del alcance real de la división de poderes. Como se sabe, a "el supremo legislador" algunas veces se le denomi-

25 TP, p. 83.

26 TP, p. 81. 
na pueblo, otras veces princeps o "monarca" (que en una constitución republicana, se supone que no tiene facultades para legislar sino para ejecutar las leyes), otras veces se identifica con los representantes del pueblo, la mayoría de las cuales es el soberano, y finalmente se le confunde con la república. Kant no fue claro en la forma y el porqué se separan pueblo y legislador supremo en dos entidades separadas y en última instancia opuestas (lo cual lo conduce siempre a volver sobre el tema de la desobediencia a la ley) ni acerca de cómo la voluntad general se transforma en voluntad del legislador y ésta en la ley. Es por ello que la "voluntad pública" como voluntad común y general ocupa un lugar fundamental pero elusivo. Por un lado, en el plano empírico, se transforma en el acto de elección de los representantes, después de lo cual parece disolverse. ${ }^{27}$ Por otro lado, en el plano trascendental, la voluntad del legislador es antes que nada, la voluntad universal, el principio práctico de la razón, que funda la soberanía de la ley, por encima del pueblo y del legislador. En principio entonces, el problema queda formulado y encuadrado pero también abierto: ¿cómo ligar la racionalidad a priori de la ley con la constitución de una voluntad colectiva? La ley jurídica, en tanto ley, es un criterio racional pero en cuanto ley positiva es un dato, una realidad provista de potencia externa.

27 “Toda verdadera república no es ni puede ser más que un sistema representativo del pueblo, instituido para la protección de sus derechos, en su nombre, es decir, en nombre de todos los ciudadanos reunidos y a través de sus delegados. Pero desde el momento en que un jefe de Estado en persona (bien sea el rey, la nobleza o todo el pueblo en su conjunto) se hace representar, entonces el pueblo reunido ya no representa solamente al soberano, es él mismo el soberano, porque en él (en el pueblo) reside originariamente el poder supremo ... y la república, una vez que ha sido establecida no tiene ya necesidad de dejarse escapar de las manos las riendas del gobierno y deponerlas en quienes las tuvieron antes (es decir, el pueblo) y que ahora podrían destruir de nuevo, con su arbitrio absoluto, todas las nuevas instituciones." PP, p. 159. 
La racionalidad de la ley, dada a priori, debe abstraerse de los intereses empíricos y medirse por la razón, pero en cuanto ley jurídica anticipa una comunidad racional que debe sancionar particularidades reales. ${ }^{28}$ Una ley que debe anticiparse al pueblo en tanto ley a priori, pero al mismo tiempo debe ser su expresión (en tanto todos deben ser racionalmente convencidos), que debe prescindir de los intereses empíricos y las voluntades particulares, pero que no puede negar el dinamismo y la competencia de los intereses privados.

El carácter público en el segundo sentido (explícito, formulable, opuesto a secreto) de la voluntad pública es más claro. Como hemos visto, la intención secreta no refiere al bien de la comunidad, en cambio la apelación a una formulación y fundamentación "pública" de las normas permite atender a su alcance general, a su aplicabilidad a una serie de situaciones, a su abstracción respecto de situaciones particulares y a la posibilidad de corrección.

En el tercer sentido, el de "abierto a todos", es conocida la distinción (no sólo) kantiana entre los diversos modos de participación en la formulación de la voluntad colectiva y sus argumentos en defensa de la limitación del sufragio a los propietarios. El argumento se basa fundamentalmente en la independencia: "todos los que son libres e iguales bajo las leyes públicas existentes deben ser considerados iguales, pero no en relación con el derecho a hacer las leyes". La división entre ciudadanos activos y pasivos refleja las limitaciones de una época, pero también la idea de que en principio, esa participación está "potencialmente" abierta a todos (todos pueden llegar a ser propietarios, dependiendo de su "habilidad, industriosidad y buena fortuna"). En este

28 Umberto Cerroni, Kant e la fondaziones della categoria giuridica, en Dott. A. Guiffré (ed.), Milán, 1962. 
tercer sentido, la voluntad pública y el uso público de la razón aparecen institucionalizados en el sufragio.

La formulación de la "voluntad pública" deja abierta entonces varias cuestiones. En primer lugar, la relación entre racionalidad de la ley, consenso racional y consenso empírico. En segundo lugar, la relación entre publicidad y corrección, que refiere a las constricciones que la formulación pública (forma de enunciación, fundamentación, alcance, etc.) impone a la declaración del arbitrio. En tercer lugar, la accesibilidad y tipo de participación de los ciudadanos en la elaboración y formulación de dicha voluntad pública.

4. Conclusiones provisionales: los problemas abiertos y las continuidades posibles

El tema de la publicidad pone en juego una determinada forma de relacionar política, derecho y moral. En la formulación kantiana el imperio del derecho supone en primer lugar, el respeto del derecho privado, autonomía legal del sujeto privado fundada en la autonomía moral del individuo. Pero afirmar el imperio del derecho no significa sólo la defensa de los derechos naturales sino también de la supremacía de la legalidad impuesta mediante normas generales y abstractas por encima de la voluntad de cualquiera de los particulares. La ley no es el decreto, la orden, el comando de quien está autorizado sino que en ella está contenida una racionalidad diferente, una expresión de la Razón Práctica. De manera gradual y casi imperceptible, es expresión también de esa nueva sociedad en gestación que progresivamente irá identificándose con la moralidad y la racionalidad. Sociedad compuesta por individuos libres e iguales o por un público ilustrado que sale de su minoría de edad. Tal vez sea este deslizamiento hacia lo social el punto que más interese a nuestra consideración de lo público. Distintos intérpretes han hecho notar que el 
siglo XVIII es testigo de un desplazamiento histórico de la idea de moralidad hacia la consideración de lo social. Como apunta Habermas en su ya clásico estudio: "En el siglo XVIII se disuelve la tradición aristotélica de una filosofía de la política en filosofía moral y lo 'moral', pensado en conexión con 'naturaleza' y 'razón' se extiende hacia la esfera - captada ya en sus comienzos - de lo 'social', hacia el horizonte semántico de la por entonces con tanta propiedad resaltada palabra social en el ámbito anglosajón."29 Es decir, la ley ya no es la palabra de la autoridad, ni la coacción de despliegue omnipotente de fuerza. Las relaciones jurídicas son en cambio pensadas como relaciones de obligación mutua universal conforme la libertad de todos según las leyes procedentes de la Razón Práctica, no de la autoridad.

Históricamente, la exigencia de ese otro tipo de racionalidad expresada en la ley, se enfrenta a la práctica secreta de la actividad soberana y se desarrolla en conexión con alguna forma de uso público de la razón. Comienza entonces la reversión del principio de auctoritas non veritas facit legem. Esas leyes de la razón práctica se imponen con igual fuerza a todos los individuos en tanto hombres libres, empíricamente a ésos que conforman el público ilustrado que luego se presentará como "la sociedad". Por ello, el problema de cómo pensar concretamente la relación entre moralidad, legalidad y sociedad cobra particular urgencia. En principio, el nudo del problema parece ubicarse en la naturaleza de esas leyes públicas que pueden pretender legitimidad en tanto actos de la voluntad pública de ciudadanos autónomos y consociados. Es decir en la forma de interpretar el principio de la soberanía popular. Las fórmulas generales aceptables por cualquier persona dotada de razón encarnan en la ley y es esta aceptación real o potencial la que

29 Habermas, HC, p. 136. 
funda su legitimidad. Más que de legitimidad vía procedimiento democrático, en el caso de Kant, tal vez podríamos hablar del intento de unir la formación de la voluntad política del legislador con "las condiciones" del procedimiento democrático (el consentimiento). En esas condiciones, los resultados logrados en conformidad con los procedimientos expresan la voluntad concurrente o el consenso racional de los participantes. Pero afirmar la moralidad pensada en conexión con lo social plantea el dualismo entre el hombre fenoménico (el individuo con sus intereses privados), la comunidad racional y la persona por otra parte. La esfera pública ilustrada resolverá el dualismo al pensarse como "privados reunidos en calidad de público", es decir, no como reunión de hombres volcados hacia la realización de sus intereses particulares sino como ciudadanos que se dirigen hacia lo general y común. Y esto tiene que ver con la preservación de sus derechos naturales y con las condiciones generales para la prosecución de la felicidad de cada uno a través de normas generales y abstractas. En la ley confluyen lo justo y lo justificado, ante el tribunal de la razón y ante el público.

Para Kant, la coincidencia entre la razón individual (o el asentimiento racional) y la voluntad legisladora a priori parece plantearse en dos niveles. El primer nivel refiere a la Constitución en sentido estricto, a las leyes fundamentales que garantizan los derechos y dan estructura jurídica al Estado. Aquí, el fundamento racional consensual está dado en el contrato como idea de razón. Nadie podría dejar de querer racionalmente la libertad, la igualdad y el reconocimiento de la autonomía, expresados en los derechos naturales. La referencia al público concreto no es necesaria. Un segundo nivel refiere a decisiones políticas expresadas en normas vinculantes que se encuadran dentro de las leyes más generales. La publicidad supone aquí coincidencia con la razón expresada en la Constitución, concordancia con los 
tres principios fundamentales, y capacidad de universalización de la máxima. El público es un referente activo, que puede contrastar o verificar (aunque no cuestionar prácticamente ni desobedecer) esa concordancia. Aquí, para la acción de gobierno, no se trata simplemente de obedecer a las leyes positivas sino de tener en cuenta la felicidad del público: el bienestar. Y es la publicidad (discusión abierta, formulación explícita, y más adelante, principio organizativo de la actividad de los órganos estatales) la encargada de esclarecer el núcleo inteligible en la unificación de las voluntades empíricas de todos. La generalidad de la conciencia empírica obtendrá así su carta de ciudadanía: la opinión pública. La publicidad es entonces, también, el recurso para racionalizar el poder en un doble sentido: poniendo por encima de la discrecionalidad y el arbitrio a la racionalidad de la legalidad y poniendo en contacto procesos legislativos y ciudadanos, representantes y electores como miembros de un mismo público. No en vano, junto con el principio de obediencia y de la irresistibilidad del poder del Estado, Kant defiende el "espíritu de libertad" que supone tomar en consideración que "en lo que refiere a las obligaciones generales de los hombres, cada individuo debe estar convencido por la razón de que la coacción es justa, de otra manera entraría en contradicción consigo mismo." ${ }^{30}$ Kant percibe claramente que la exigencia de obediencia sin aceptación, de la coacción sin consenso es y ha sido siempre la causa de las "sociedades secretas". Y las sociedades secretas son la versión invertida y perversa del espacio público ilustrado. Es la justificación pública entonces, la presencia "real o potencial" de ese público, la que hace coincidir, en otro nivel, la legalidad y la razón.

Y ello nos lleva a la forma de pensar la política, y al matiz que detectábamos. En los textos analizados, la política

${ }^{30}$ Kant, TP, p. 85. 
está en general caracterizada como aplicación del derecho y como extensión de la moral. Por otro lado, en algunas formulaciones (no sólo las que refieren a la autoridad) aparece como una esfera o un tipo de práctica diferente, que refiere a las relaciones de poder y dominación, y está ligada a la naturaleza tanto en lo que respecta a la aplicación del poder coercitivo (elemento definitorio del derecho estricto) como en lo que hace al cálculo prudencial.

Así por un lado Kant nos dice: "Pero si se cree que es absolutamente necesario unir el concepto del derecho a la política y hasta elevarlo a la altura de condición limitativa de la política, entonces hay que admitir que existe una armonía posible entre ambas esferas"31 (moral y política). La armonía es posible porque también es posible el conflicto, por lo que se impone el derecho como condición limitativa. La prudencia política no es directamente aplicación de la moralidad pero es compatible, en algunos casos, con ella. Como vimos, Kant no sólo pone ejemplos de incompatibilidad, sino también plantea casos en los que la prudencia política no desafía la moral. Entonces en varias formulaciones la diferenciación entre moral, derecho y política así como sus posibles relaciones y conflictos es explícita. En otras partes, en cambio, la política parece reducirse a la aplicación del derecho y éste a su fundamentación moral. "No puede haber, por tanto, disputa entre la política, como aplicación de la doctrina del derecho y la moral, que es la teoría de esa doctrina; no puede haber disputa entre la teoría y la práctica." Quizá la formulación más clara, tanto en lo que respecta a la autonomía como a la subordinación de una esfera respecto de la otra sea aquella en la que Kant dice: "La política en sí misma, es un arte difícil, pero la unión de la política con la moral no es un arte, pues tan pronto como surge entre ambos una discrepancia,

31 PP, p. 136. 
que la política no puede resolver, viene la moral y zanja la cuestión, cortando el nudo. El derecho debe prevalecer." Una cosa es caracterizar la política sólo como aplicación de la doctrina del derecho cuyo fundamento a su vez es la moral, y otra es plantear que el derecho es una condición limitativa y un factor de racionalización de la política. En el primer caso las diferencias entre política, derecho y moral parecen diluirse, y la política se reduce o bien a la aplicación de la legalidad (jurídica o moral) o bien es "baja política", "politiquería". En cambio, en el segundo caso, las fronteras entre un margen de decisión prudencial y de cálculo estratégico, el encuadramiento jurídico y el juicio moral son claras. Esto aparece claramente en la referencia de la política al "bienestar" y en el ejemplo de los impuestos, donde la consideración de la idoneidad de los medios para los fines propuestos no se sustraía de la consideración jurídica propiamente dicha pero sí de la crítica del público. La legalidad era condición limitativa de la utilización de medios, pero su consideración, más allá o más acá de la legalidad, era objeto de un cálculo prudencial.

Con esto quiero adelantar la hipótesis interpretativa de que en Kant coexisten varias líneas: una que tendencialmente apunta al ideal de una política moral, basado en el actuar recto a partir del deber bajo leyes positivas en una situación completamente normada por el derecho. En su función regulativa, el ideal orientará la conducta de los políticos morales y también, en otro sentido, guiará el progreso hacia lo mejor en la perspectiva de la filosofía de la Historia. Otra línea sentará las bases de una crítica moral a la política, entendida ésta como pura relación de poder arbitrario. Indicios de esta crítica moral aparecen en ciertos aspectos del planteo kantiano. La subordinación estricta de la política a la moral universal y la creencia en que esta última "corta el nudo" de todo conflicto, preanuncia la idea de que toda consideración estratégica puede y debe 
ser juzgada en términos morales. En Kant, esta posibilidad aparece equilibrada por el reconocimiento del lugar de la soberanía de la ley (recalcando el aspecto de coercibilidad del derecho y de irresistibilidad de la ley). Es decir, por una línea que apunta al tema del Estado jurídico como expresión de la soberanía popular, pero también como condición de su unidad jurídica. Un Estado entonces que no es pura razón ni es pura naturalidad. Un Estado que, ordenado por el derecho se previene de la tentación paternalista, pero que para ser tal, requiere del poder irresistible. Es esta última línea la que otorga sentido al alcance políticamente limitado del uso público de la razón, del ámbito ilustrado de debate. Éste conecta la legitimidad de la legalidad con el convencimiento racional de cada uno de los participantes de ese espacio público y en ese sentido abre el camino de la "crítica" (es decir, de la posibilidad de someter la validez de las normas al tribunal de la razón), pero limita su alcance a una esfera cuya autonomía debe ser garantizada en el marco de la soberanía del Estado de derecho.

Una vez desaparecida esta limitación, la moralidad se transformaría en el único criterio de evaluación política. Y su plena identificación con "la voz" de esa nueva sociedad llevará a erigir a la moralidad en tribunal del Estado. Este desborde "perverso" de la crítica radicalizada es el eje que retomará un Carl Schmitt y en su línea, Reinhart Kosseleck. En Kant el uso público de la razón no se contrapone a la soberanía estatal. En cambio, para esta línea de pensamiento, la crítica moral a la política, encarnada en una autodenominada "sociedad civil" que se enfrenta al Estado, será tematizada en términos de "crisis" de la soberanía.

La constitución de la voluntad "pública" y su relación con los intereses privados de los individuos seguirá también siendo fuente de perplejidades. En Kant, el Estado (de derecho) aparece como función de una comunidad, o 
mejor dicho, instaura una comunidad de privados, de individuos que tienen valor ante y fuera de la sociedad. Por otro lado, se convoca la entrada en la sociedad estatal para racionalizar esa disociación o esa atomización, garantizando de todos modos el primado del individuo. La voluntad pública se constituye con base en los tres principios a priori de la libertad, la igualdad y la autonomía. Es voluntad pública en tanto que común, aunque para su comprensibilidad remite en última instancia a las voluntades privadas. La subordinación del estado al derecho, a una norma de razón positivizada que sea capaz de unificar en una comunidad la heterogeneidad de los intereses privados, permite el pasaje del derecho privado al derecho público. Pero además de su fundamentación racional, el orden jurídico surge y se justifica sobre el presupuesto de seres que operan bajo el estímulo de la utilidad y de la felicidad, y que crean el Estado para regular racionalmente la incorporación de la libertad empírica en una sociedad jurídica. Sociedad que permita por un lado la máxima libertad y, por tanto, el antagonismo y, por otro, que determine y garantice del modo más riguroso los límites de libertad de cada uno, para poder hacerla coexistir con la libertad de los demás. En última instancia la libertad para poder procurarse la felicidad privada sin interferencias externas termina siendo, en vena liberal, la clave de toda la construcción del orden jurídico y político. El derecho público termina subordinándose al derecho privado. La tensión entre felicidad privada y "felicidad pública", la relación entre las garantías para las libertades civiles y el reparto del poder, o en otros términos, la cuestión no del todo clarificada en Kant entre la autonomía moral de los individuos y las formas de ejercicio de la autonomía política, serán temas recurrentes que, en clave republicana, la teoría política recupere una y otra vez.

La naturaleza del consenso racional que se logra públicamente, sus posibilidades y límites será el aspecto de la pu- 
blicidad que recuperará fundamentalmente la llamada ética discursiva. ¿Cómo se vinculan (en condiciones de complejidad social) legalidad y formación discursiva, jurídicamente garantizada, a la voluntad colectiva del público de ciudadanos? El pasaje sin fisuras desde una razón individual a una racionalidad moral universal será elaborado otra vez en función tanto de la interpretación de las necesidades colectivas como del "punto de vista moral". También la racionalidad de la ley, emanada en Kant de la referencia al acuerdo constituyente y a los tres principios a priori, será cuestionada y replanteada a partir del análisis de los procedimientos discursivos de formulación y de su referencia a un conjunto de razones y motivos presentes en la esfera de la publicidad. En esta vertiente, se tratará de desarrollar la dimensión democrática en sentido moderno, ambiguamente presente en Kant.

La idea de legitimidad con base en la legalidad está ya presente en Kant, no tanto en función de los procedimientos correctos sino fundamentalmente a partir de la naturaleza fundacional de la Constitución. La cuestión, a través de Weber, llegará a Luhmann, quien dará una respuesta diferente al problema de la relación entre decisión y opinión pública. Habíamos visto como en el ejemplo de la formulación de una ley particular, aparecía en Kant un núcleo "separado" de las consideraciones morales (en términos de inevitabilidad, de oportunidad, etc.) que parecía remitir a un elemento de "decisión" política incapaz de ser neutralizado o disuelto por consideraciones morales pero que seguía siendo encuadrado y legitimado jurídicamente. Tal vez, en este tema, sea Luhmann quien recupera ese núcleo "decisionista" irreductible. Decisión que sin embargo no se independiza de la opinión pública ni del sistema jurídico. Por el contrario, legalidad y opinión pública aparecerán como límites de lo posible y como reductores de la contingencia y la arbitrariedad. 
Tal vez todos estos problemas remitan en última instancia a algo que va más allá de nuestro tema específico: a la realidad del derecho, a esa caja de Pandora que abriera Kant al determinar la autonomía de la categoría jurídica afirmando al mismo tiempo su relación con la moral y con la política. A esa extraña capacidad del derecho de ordenar el mundo de las relaciones sensibles según valores y de otorgar a los valores, como ordenadores eficaces de lo real, el apoyo de una positividad. A esa naturaleza bifronte que ha llevado a intentar defender su autonomía y su pureza o a disolver su especificidad en la naturaleza o la moralidad. A esa realidad dual que hace que los viejos temas vuelvan a replantearse: el conflicto entre legalidad y justicia, entre legitimidad y eficacia del derecho, entre derecho estricto y derecho justo. Es decir, la indisoluble conexión entre legalidad y esfera de lo público. Pero también sacan a la luz una relación aún más central para nuestra reflexión: la que une un concepto normativo de la esfera de lo público con la democracia moderna. Éstos no fueron estrictamente los términos de Kant. Tampoco sus preferencias se orientaban hacia lo que hoy llamaríamos ideales o configuraciones democráticas. Sin embargo, el papel de la esfera pública ilustrada y de la "publicidad" en su pensamiento político dibujan un campo de problemas que hasta hoy desvelan a la teoría política. Y que, traducidos a la altura de las "sociedades complejas", prueban ser desvelos justificados. 


\section{SUMMARY}

Kant rehabilitates, in his so-called "political writings" and in his philosophy of law, the notion of public reason as a control instance of legislation and of the political measures which affect a community. The "public use" of reason fulfills, in the first place, a basic task of enlightment. But it also has other ramifications. By means of the formulation of the publicity principle, the predicate "public" (in the sense of something being visible) can be brought to bear on the practicing of power. And finally, presupposing a public use of reason may allow us to reach public coincidence, i.e., a consensus in the elaboration of the rational will. The first goal of the paper is to examine the political scope of such rehabilitation of public reason. The second goal is to formulate a number of problems which emerge, since Kant, whenever the issue of public space is approached. Finally, a few questions are posed bearing on Kant's conception of politics: although politics appears to fall under the larger categories of morals and law in Kant's writings, the author seems in some places to hint at a recognition of a prudential sphere for politics alone which, however, must be made compatible with morals and law.

[Traducción: Héctor Islas] 